$\mathbb{T}$ periodica polytechnica

Chemical Engineering

$55 / 1(2011) 11+16$

doi: 10.3311/pp.ch.2011-1.02

web: http://www.pp.bme.hu/ch

(c) Periodica Polytechnica 2011

RESEARCH ARTICLE

\section{Investigation and modeling of lactic acid fermentation on wheat starch via SSF, CHF and SHF technology}

\author{
Kata Hetényi / Áron Németh / Béla Sevella
}

Received 2010-10-13

\begin{abstract}
Starch based lactic acid fermentation technology was examined and optimized using a non-amylolitic, mesophilic lactic acid bacterium. Comparing simultaneous saccharification and fermentation (SSF) and separate hydrolysis and fermentation $(S H F)$ technologies several issues arose and applying the two techniques needed several compromises concerning the overall process time. A combined hydrolysis and fermentation method was developed which incorporate the advantages of SSF and SHF technologies: applying a time delay in inoculation and cutting down hydrolysis time before fermentation, an optimal inoculation and high efficiency was achieved by kinetic model aided experimental work. Experimental verification of the model gave an excellent productivity result: $4.32 \mathrm{~g} \mathrm{~L}^{-1} h^{-1}$ calculated with only the fermentation time, and $2.88 \mathrm{~g} \mathrm{~L}^{-1} h^{-1}$ calculated with the overall time of the two processes. With this method, hydrolysis and fermentation time was successfully reduced, enhancing lactic acid productivity and depressing production cost of this low-value chemical.
\end{abstract}

\section{Keywords}

Kinetic model; Lactic acid; Separate hydrolysis and fermentation; Simultaneous saccharification and fermentation; Starch hydrolysis.

\section{Acknowledgement}

This work was supported by HUNEST Biorefinery Ltd. We also wish to thank Palus Ltd. for providing Novozymes enzyme products for hydrolysis processes.

\section{Kata Hetényi}

Áron Németh

Department of Applied Biotechnology and Food Science, BME, H-1111 Budapest Múegyetem rkp 3, Hungary

\section{Béla Sevella}

Department of Applied Biotechnology and Food Science, BME, H-1111 Budapest Múegyetem rkp 3, Hungary

e-mail: bsevella@mail.bme.hu

\author{
Abbreviations \\ $S \quad$ Starch concentration $\left(\mathrm{g} \mathrm{L}^{-1}\right)$ \\ MD Maltodextrin concentration $\left(\mathrm{g} \mathrm{L}^{-1}\right)$ \\ $G \quad$ Glucose concentration $\left(\mathrm{g} \mathrm{L}^{-1}\right)$ \\ $X \quad$ Biomass concentration $\left(\mathrm{g} \mathrm{L}^{-1}\right)$ \\ $L A \quad$ Lactic acid concentration $\left(\mathrm{g} \mathrm{L}^{-1}\right)$ \\ $N \quad$ nitrogen source concentration $\left(\mathrm{g} \mathrm{L}^{-1}\right)$ \\ $T \quad$ Temperature (K) \\ $R \quad$ Universal gas constant \\ $t \quad$ time \\ $E_{z} \quad$ activation energy of $\mathrm{z}$ parameter according to Ar- \\ rhenius $\left(\mathrm{J} \mathrm{mol}^{-1}\right)$ \\ $A_{z} \quad$ preexponential constant of $\mathrm{z}$ parameter according \\ to Arrhenius (depends on dimension of $\mathrm{z}$ \\ $r_{n} \mathrm{n}^{s t} \quad$ reaction rate $\left(\mathrm{g} \mathrm{L}^{-1} \mathrm{~h}^{-1}\right)$ \\ $k_{\text {cat }} \quad$ turnover number of $\alpha$-amylase depending on tem- \\ perature $\left(\mathrm{h}^{-1}\right)$ \\ $K_{m} \quad$ Michaelis constant of $\alpha$-amylase depending on \\ temperature $\left(\mathrm{g} \mathrm{L}^{-1}\right)$ \\ $K_{N} \quad$ Halfsaturation constant of nitrogen source $\left(\mathrm{g} \mathrm{L}^{-1}\right)$ \\ $k_{1} \quad$ growth associated constant of product formation \\ according to Luedeking Piret \\ $k_{2} \quad$ non-growth associated constant of product forma- \\ tion according to Luedeking Piret $\left(\mathrm{h}^{-1}\right)$ \\ $Y \quad$ biomass yield on glucose $\left(\mathrm{g} \mathrm{g}^{-1}\right)$ \\ $Y_{N} \quad$ biomass yield on nitrogen source $\left(\mathrm{g} \mathrm{g}^{-1}\right)$ \\ $Y_{P} \quad$ product (LA) yield on glucose $\left(\mathrm{g} \mathrm{g}^{-1}\right)$
}

\section{Introduction}

Lactic acid is a low-value, higher-volume bulk chemical and it could be used as feedstock for biodegradable polymers (PLA), environmentally friendly solvents (ethyl-lactate, butyl-lactate etc.), and chemical intermediates. For the production of L-(+)lactic acid microbial synthesis of the pure isomer is preferred, because the chemical route results in a racemic mixture whose separation is difficult. The use of excess biomass or agricultural and industrial wastes to produce lactic acid via fermentation is not a novelty, however in Hungary a proposal has recently been advanced to use surplus grain capacity (corn, wheat, 
sweet sorghum) in white-industrial technologies [7]. In these technologies it is important to use every fraction of the grain, so that with a well-chosen technology it can satisfy every demands of producing bacteria without any or with minimal amount of supplementation.

Wheat is an appropriate raw material for bacterial lactic acid fermentation because its starch content can cover carbon source need of lactic acid bacteria, while protein content serves as nitrogen source for their growth. According to the literature [15] and to our previous experiments (Hetényi et al. 2008, personal communication) in case of Lactobacilli other needs may come up (vitamins, salts, amino acids etc.) as well, which can be satisfied by combining a minimal yeast extract supplementation with another nitrogen containing media component, in case of wheat the insoluble protein fraction of the corn (gluten) [8].

Using starch as carbon source can be handled in different ways: some lactic acid producing strains can convert starch to lactic acid without previous hydrolysis (direct fermentation) [23]; in some cases an enzymatic starch liquefaction step precedes fermentation to enhance the hydrolysis and then the strain's own gluco-amylase enzyme converts dextrins to glucose for lactic acid fermentation (Lactobacillus amylophilus [1.2. 14], Lactobacillus amylovorus [4], Lactobacillus manihotivorans [13], Rhizopus oryzae [5, 6]; most lactic acid bacteria (most of lactobacilli, lactococci etc.) need complete hydrolysis to glucose which can be performed by separate hydrolysis and fermentation (SHF) [25] or in line with fermentation (simultaneous saccharification and fermentation - SSF) [9, 20, 22]; the simultaneous saccharification and fermentation could be solved by co-fermentation as well by joint use of an amylolytic fungus and a lactic acid bacterium [24].

Microbial conversion of starch to lactic acid can be made much more economical by coupling the enzymatic hydrolysis of starchy substrates and microbial fermentation of the derived glucose in one single step. A direct benefit of SSF process is a decrease in the substrate inhibition caused by glucose and a consequent reduction in reactor volume and capital costs besides time consumption [3].

Normally lactic acid bacteria are mesophiles while normal hydrolysis of starch is done at elevated temperature, accordingly the temperature optimum of the microorganism and that of the hydrolyzing enzymes do not overlap. This problem have been solved by some successful experiments on simultaneous enzymatic saccharification and fermentation [23]. One method is using thermophilic bacteria or fungi, which is advantageous partly because the temperature optima of the strain and of the enzyme border on each other, partly it can eliminate inhibition caused by high sugar concentration, and elevated temperature even reduces infection problems at an industrial scale [3, 10].

In case of a lignocellulosic hydrolysis and lactic acid fermentation Parajo et al. [17] applied different hydrolysis duration at the optimal temperature of the enzymes, then inoculated the hydrolysate and examined SSF process at temperature optimum of a mesophilic lactic acid producing bacterium (combined hydrolysis and fermentation - CHF). Linko and Javanainan [12] examined commercial starch hydrolyzing enzymes in SSF processes at different temperatures, including the optimum temperature $\left(37{ }^{\circ} \mathrm{C}\right)$ of a mesophilic lactobacillus and compared the results to one at a more elevated temperature. They concluded that the fermentation efficiency ameliorated.

Targets of our experiments are to produce lactic acid on a previously optimized [7, 8] wheat flour based medium, comparing SHF and SSF technology experimentally and by modeling, to reduce hydrolysis and fermentation time, hereby enhancing lactic acid productivity and depressing production cost of this lowvalue chemical.

\section{Materials and methods}

\subsection{Microorganism}

Lactobacillus sp. MKT-878 NCAIM B02375, a facultative anaerobic homofermentative L-lactic acid producer was obtained from an earlier strain selection program in our research group. The strain was stored on MRS medium agar slants (Difco, USA) at $4{ }^{\circ} \mathrm{C}$.

\subsection{Culture conditions}

Precultures for laboratory fermentation experiments were prepared by transferring a stock culture onto two slants of MRS agar and incubating at $37{ }^{\circ} \mathrm{C}$ for $24 \mathrm{~h}$. Cells were harvested in sterile water and the cell suspension was transferred by a sterile syringe into the bioreactor.

Four 1 liter (B. Braun Biostat $($ Q Q 800/1000 mL) fermentors were employed for fermentations. Agitation speed and culture temperature were controlled at $500 \mathrm{rpm}$ and $37{ }^{\circ} \mathrm{C}$ respectively, the $\mathrm{pH}$ was regulated at 5.5 by $25 \% \mathrm{H}_{2} \mathrm{SO}_{4}$ and $20 \% \mathrm{NH}_{4} \mathrm{OH}$ for liquefaction and saccharification steps, but during fermentation lactic acid production was buffered by $\mathrm{CaCO}_{3}$ (added in stoechiometrical amount) between $\mathrm{pH}$ 6.5-4.5.

The fermentors, their accessories and $\mathrm{CaCO}_{3}$ were sterilized in autoclave at $121{ }^{\circ} \mathrm{C}$ for $20 \mathrm{~min}$. The wheat hydrolysate did not need sterilization because of the high hydrolysis temperature used.

\subsection{Media and hydrolysis}

\subsubsection{Raw materials}

The base of media was wheat flour type 550 (all-purpose commercial flour, with $0,55 \%$ ash content) with a protein content of $11 \%$ dry weight and a wet gluten content of $27 \%$.

The starch content (65\% dry weight) of wheat flour was degradable in two enzymatic steps, by liquefaction of starch and by saccharification of oligosaccharides.

Medium preparation: after adding $166 \mathrm{~mL}$ tap water to $200 \mathrm{~g}$ wheat flour, 1 hour kneading and addition of $208 \mathrm{~mL}$ tap water with $16.4 \mu \mathrm{L}$ Shearzyme $\mathbb{R}$ 500L enzyme (Novo Nordisk, Denmark) was carried out for the protein agglomeration process. Gluten fraction was separated by centrifugation (30 min, 
3000 rpm, Janetzky K70 D centrifuge), followed by washing with water, and diluting the starch suspension up to $1000 \mathrm{~mL}$. After preparing gluten-free medium starch, $16 \mathrm{~g} \mathrm{~L}^{-1}$ vital gluten (Victory 2001 Ltd., Hungary) and $6 \mathrm{~g} \mathrm{~L}^{-1}$ yeast extract (Reanal Budapest, Hungary) were added which is the optimized amount of supplementation for this strain [8]. Then the liquefaction and saccharification process was carried out.

\subsubsection{Hydrolysis}

For hydrolysis steps we followed instructions of Novo Nordisk product sheets.

In $1 \mathrm{~L}$ of wheat flour based medium the liquefaction of starch was carried out for $40 \mathrm{~min}$ by $56 \mu \mathrm{L}$ Termamyl $\mathbb{R}$ SC $(\alpha$ amylase by Novo Nordisk), at $85^{\circ} \mathrm{C}$ and $\mathrm{pH}$ 5.5. For the saccharification of oligosaccharides and proteolytic digestion of gluten

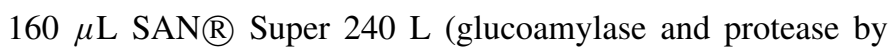
Novo Nordisk), $55{ }^{\circ} \mathrm{C}$ and $\mathrm{pH} 5.5$ was used, with different prehydrolysis (i.e. inoculation) time: 0 (SSF), 12, 24, 36 (SHF) hours, and finally with an optimized duration.

Hydrolysis were performed in 1 liter B. Braun Biostat $(\mathrm{Q})$ fermentors $(500 \mathrm{rpm}, 500 \mathrm{~mL})$.

\subsection{Analyses}

Substrates and products were analyzed by HPLC (Waters Breeze HPLC System, BioRad Aminex HPX-87H column on $65{ }^{\circ} \mathrm{C}$, mobile phase: $5 \mathrm{mM} \mathrm{H}_{2} \mathrm{SO}_{4}$ at flow rate of $0.5 \mathrm{~mL}$ $\min ^{-1}$ ).

To measure optical density we had to use $0.2 \mathrm{~N} \mathrm{HCl}$ for tenfold dilution of samples to dissolve the residual $\mathrm{CaCO}_{3}$ but it resulted in precipitation of wheat proteins which disturbed the optical density measurements. Accordingly we did not measure the optical density.

\subsection{Setting up a kinetic model}

A lactic acid fermentation model following Monod growth kinetics and Luedeking-Piret production kinetics was already verified (on the basis of batch experiments on a glucose based medium) and reported elsewhere [16]. This model was modified, re-verified and further supplemented with a temperature dependent starch hydrolysis description (Table 2). The temperature dependency of the liquefaction step was adapted from the approach of Rodriguez et al. [7], but in term of saccharification the literature is very confused, giving constants referring to starch or maltodextrins (including maltose, maltotriose, trehalose etc. according to the enzyme substrate spectrum) with or without temperature dependency [11, 18]. For this reason we followed the glucose formation during saccharification experiments at different temperatures $\left(37-42-47-55{ }^{\circ} \mathrm{C}\right)$, fitted an exponential curve $\left(G=a \cdot\left(1-\exp ^{-b \cdot t}\right)\right)$ by Sigma Plot 2001 software, and with linearization determined the Arrhenius temperature dependency of the constants ( $a$ and $b$ ) in the fitted exponential function (listed in Table 11). For modeling purposes we assumed that starch is first converted by $\alpha$-amylases into "general maltodextrins", and then maltodextrins will be converted by gluco-amylases into glucose, which is in small part converted into biomass but mostly into lactic acid (Fig. 11). For biomass production nitrogenous substances (gluten, yeast extract), vitamins (principally from yeast extract), energy, thereby sugars are needed, and the main amount of biomass is arisen from the organic nitrogen source. The rate of saccharification was taken as the first derivative of the fitted exponential function in respect of time. The applied parameters and initial conditions are also listed in Table 1

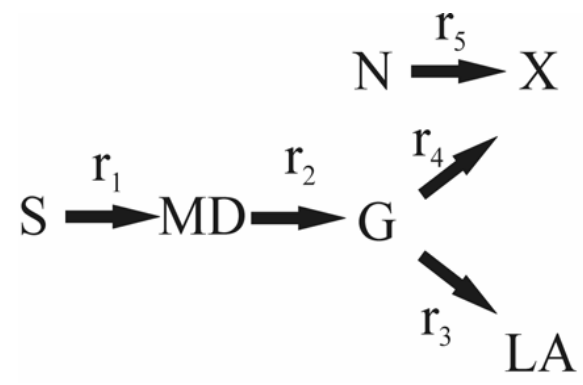

Fig. 1. Simplified scheme for kinetic of starch hydrolysis and lactic acid fermentation

\section{Results and discussion}

\subsection{Separate hydrolysis and fermentation (SHF)}

The simplest way to use starch as carbon source for lactic acid fermentation is the total hydrolysis to glucose at the optimum environment of the enzymes then inoculation of this medium with the mesophilic strain at its optimal temperature and $\mathrm{pH}$. The advantage of this process is that both the hydrolysis and fermentation run at maximal speed, but the total productivity (calculated with the sum of the time of hydrolysis and fermentation) is lower.

The medium contained $125 \mathrm{gL}^{-1}$ glucose after total hydrolysis (liquefaction and 36 hours of saccharification), and the fermentation gave as good results as in our previous experiments during wheat based medium optimization process [8]: the strain converted glucose into lactic acid with $94 \%$ yield (calculated from the amount of the produced lactic acid and consumed glucose) and $3.57 \mathrm{~g} \mathrm{~L}^{-1} \mathrm{~h}^{-1}$ productivity results (Fig. 2, Table 2). However the productivity considering also the time of hydrolysis was less satisfactory. To reduce the overall time of the process and for higher productivity result we turned to SSF technology.

\subsection{Simultaneous saccharification and fermentation (SSF)}

During simultaneous saccharification and fermentation microbial conversion of glucose to lactic acid is in line with saccharification (after a liquefaction step at high temperature), so the problem of a potential substrate inhibition is solved, but the enhancing effect of the high initial substrate concentration on the conversion is eliminated. The temperature and the $\mathrm{pH}$ of the 
Tab. 1. Model equations, parameters and initial conditions

\begin{tabular}{|c|c|c|c|c|}
\hline & Balance equations & Rate expressions & Parameters & $\begin{array}{l}\text { Initial conditions } \\
(\text { at } t=0)\end{array}$ \\
\hline Hydrolysis & $\begin{array}{l}\frac{d S}{d t}=-r_{1} \\
\frac{d M D}{d t}=r_{1}-r_{2}\end{array}$ & $\begin{array}{l}r_{1}=k_{\text {cat }} \cdot E_{\text {amylase }} \cdot \frac{S}{K_{m}+S} \\
k_{\text {cat }}=A_{k} \cdot e^{\frac{E_{k}}{R \cdot T}} \\
K_{m}=A_{K m} \cdot e^{\frac{E_{K m}}{R \cdot T}} \\
r_{2}=a \cdot b \cdot e^{-b \cdot t} \\
a=A_{a} \cdot e^{\frac{E_{a}}{R \cdot T}} \\
b=A_{b} \cdot e^{\frac{E_{b}}{R \cdot T}}\end{array}$ & $\begin{array}{l}A_{k}=1.74 \cdot 10^{8}\left(\mathrm{~h}^{-1}\right) \\
E_{k}=-4.17 \cdot 10^{4}\left(\mathrm{Jmol}^{-1}\right) \\
A_{K m}=7.35 \cdot 10^{2}\left(\mathrm{gL}^{-1}\right) \\
E_{K m}=-2.44 \cdot 10^{4}\left(\mathrm{Jmol}^{-1}\right) \\
A_{a}=7.55 \cdot 10^{3}\left(\mathrm{gL}^{-1}\right) \\
E_{a}=-1.07 \cdot 10^{4}\left(\mathrm{Jmol}^{-1}\right) \\
A_{b}=3.73 \cdot 10^{0}\left(\mathrm{~h}^{-1}\right) \\
E_{b}=-9.03 \cdot 10^{3}\left(\mathrm{Jmol}^{-1}\right)\end{array}$ & $\begin{array}{l}\mathrm{S}_{0}=140 \mathrm{~g} \mathrm{~L}^{-1} \\
\mathrm{MD}_{0}=0 \mathrm{~g} \mathrm{~L}^{-1} \\
\mathrm{E}_{\text {amylase }}=4.2 \cdot 10^{-3} \\
\mathrm{gL}^{-1}\end{array}$ \\
\hline Fermentation & $\begin{array}{l}\frac{d G}{d t}=r_{2}-\frac{r_{3}}{Y_{P}}-\frac{r_{4}}{Y} \\
\frac{d L A}{d t}=r_{3} \\
\frac{d X}{d t}=r_{4} \\
\frac{d N}{d t}=\frac{r_{5}}{y_{N}}\end{array}$ & $\begin{array}{l}r_{3}=k_{1} \cdot \mu \cdot x \quad O R \quad r_{3}=k_{2} \cdot x \cdot \ln (S) \\
\quad\left(\mu \cong \mu_{\max }\right) \quad(\mu<\mu \max ) \\
r_{4}=\mu \cdot x \\
\mu=\mu_{\max } \cdot \frac{N}{K_{N}+N} \\
r_{5}=-r_{4}\end{array}$ & $\begin{array}{l}\mu_{\max }=0.136 h^{-1} \\
(\text { atp } H=5.8) \\
K_{N}=0.166 \mathrm{~g} \mathrm{~L}^{-1} \\
k_{1}=4.76 \\
k_{2}=0.119 h^{-1} \\
Y=0.37 \\
Y_{N}=1.5 \\
Y_{P}=0.99\end{array}$ & $\begin{array}{l}\mathrm{G}_{0}=0 \mathrm{~g} \mathrm{~L}^{-1} \\
\mathrm{x}_{0}=0.67 \mathrm{~g} \mathrm{~L}^{-1} \\
\mathrm{LA}_{0}=3.3 \mathrm{~g} \mathrm{~L}^{-1} \\
\mathrm{~N}_{0}=6 \mathrm{~g} \mathrm{~L}^{-1}\end{array}$ \\
\hline
\end{tabular}

Tab. 2. Productivity results of different processes

\begin{tabular}{|c|c|c|c|c|c|c|}
\hline Process & $\begin{array}{l}\text { Hydrolysis } \\
\text { time (h) }\end{array}$ & $\begin{array}{l}\text { Fermentation } \\
\text { time }(\mathrm{h})\end{array}$ & $\begin{array}{l}\text { Total } \\
\text { time }(\mathrm{h})\end{array}$ & $\begin{array}{l}\text { Lactic acid } \\
\left(\mathrm{g} \mathrm{L}^{-1}\right)\end{array}$ & $\begin{array}{l}\text { Productivity } \\
\left(\mathrm{g} \mathrm{L} \mathrm{L}^{-1} \mathrm{~h}^{-1}\right) \text { cal- } \\
\text { culated with } \\
\text { fermentation time }\end{array}$ & $\begin{array}{l}\text { Productivity } \\
\left(\mathrm{g} \mathrm{L}^{-1} \mathrm{~h}^{-1}\right) \\
\text { calculated with } \\
\text { total time }\end{array}$ \\
\hline SSF & 0 & 56 & 56 & 97 & 1.74 & 1.74 \\
\hline CHF 12 hours & 12 & 44 & 56 & 105 & 2.38 & 1.87 \\
\hline CHF 24 hours & 24 & 38 & 62 & 104 & 2.73 & 1.67 \\
\hline SHF & 36 & 33 & 69 & 118 & 3.57 & 1.71 \\
\hline CHF 14 hours -opimized & 14 & 28 & 42 & 121 & 4.32 & 2.88 \\
\hline
\end{tabular}

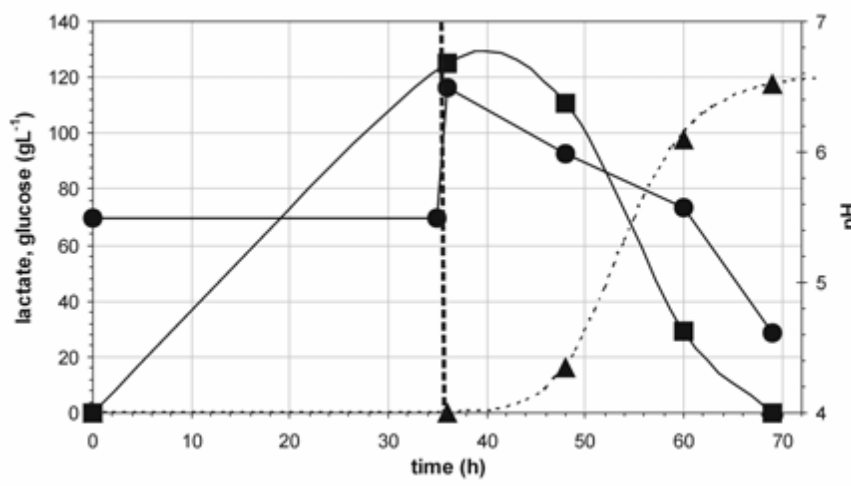

Fig. 2. Separate hydrolysis and fermentation (SHF) on wheat flour based medium, with 36 h of pre-hydrolysis: (- -$)$ glucose; (- - -) lactic acid; ($\bullet-) \mathrm{pH}$.

parallel processes can be set either to the optimum of the saccharification enzyme or to those of the microbe. In our case we chose the $\mathrm{pH}$ and temperature optimum of the strain $\left(37^{\circ} \mathrm{C}, \mathrm{pH}\right.$ 5.8) because it is moderately tolerant to the temperature deviation and its $\mathrm{pH}$ optimum is close to that of the enzyme.

The duration of saccharification and fermentation (Fig. 3) was 56 hours and the amount of residual glucose was $12 \mathrm{~g} \mathrm{~L}^{-1}$. Although starch concentration was not determined, according to our SHF experiments and previous attempts [8] after a total starch hydrolysis, the final glucose concentration was usually $120 \mathrm{~g} \mathrm{~L}^{-1}$. Accordingly the final $97 \mathrm{~g} \mathrm{~L}^{-1}$ lactic acid concentration suggests a yield $89 \%$ of that theoretically possible (assuming total starch hydrolysis). The productivity (considering only fermentation time) was $1.74 \mathrm{~g} \mathrm{~L}^{-1} \mathrm{~h}^{-1}$ (Table 2), the half of the results previously described with this medium $\left(3.54 \mathrm{~g} \mathrm{~L}^{-1} \mathrm{~h}^{-1}\right)$, because of the very low substrate concentration during the whole process.

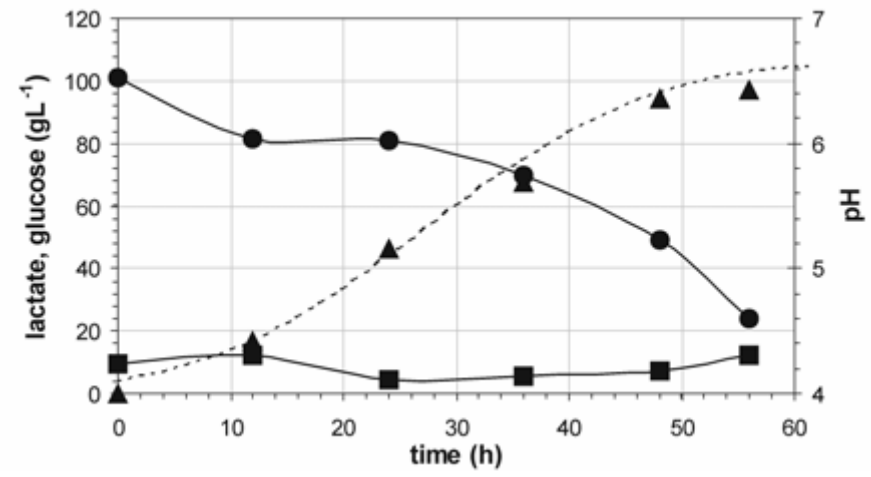

Fig. 3. Simultaneous saccharification and fermentation (SSF) on wheat flour based medium, with $0 \mathrm{~h}$ of pre-hydrolysis: (_-) glucose; (_- lactic acid; (-

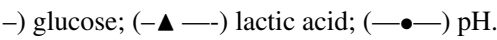




\subsection{Combined hydrolysis and fermentation (CHF)}

According to our previous experiments [8], to reach the maximal starch hydrolysis rate we applied 36 hours of saccharification on the enzyme optimum. In case of combined hydrolysis and fermentation we tried to find an appropriate inoculation time point where the initial glucose concentration is high enough to enhance lactic acid conversion, but the length of hydrolysis does not increase significantly the overall process time (comprising both hydrolysis and fermentation time). During hydrolysis, $\mathrm{pH}$ and temperature were set to the optimum for the saccharifying enzyme $\left(55^{\circ} \mathrm{C}, \mathrm{pH} 5.5\right)$ thus speed of saccharification was maximal, then we shifted them on the optimum of the strain $\left(37^{\circ} \mathrm{C}\right.$, $\sim \mathrm{pH} 6.5$ by $\mathrm{CaCO}_{3}$ ) to ensure maximal lactic acid conversion rate.

The two tested inoculation time points were 12 (Fig. 4) and 24 hours (Fig. 5).

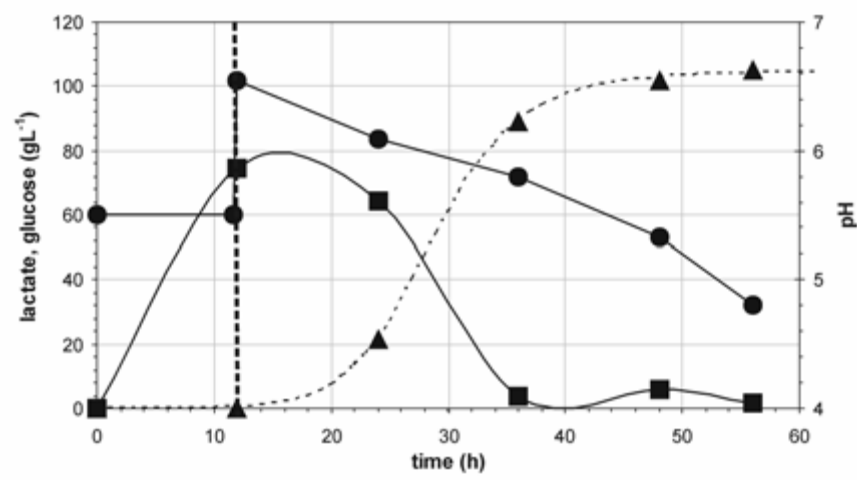

Fig. 4. Combined hydrolysis and fermentation (CHF) on wheat flour based medium, with $12 \mathrm{~h}$ of pre-hydrolysis:(- -$)$ glucose; (- - -) lactic acid; (--) $\mathrm{pH}$.

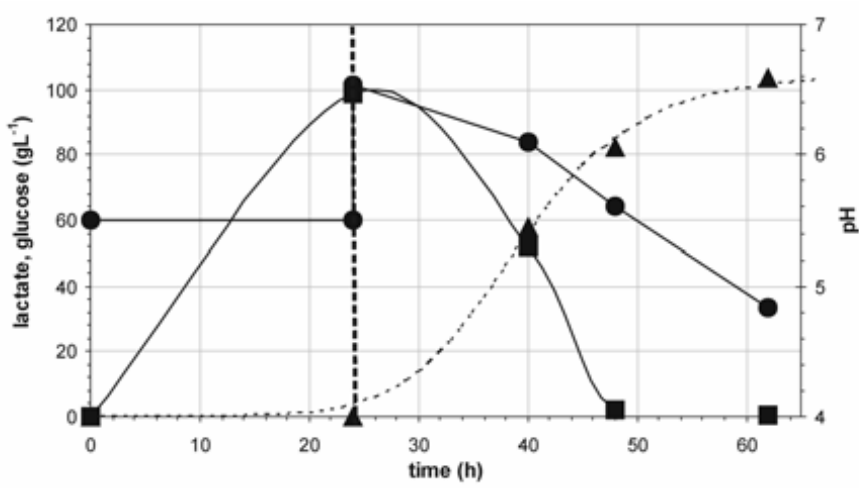

Fig. 5. Combined hydrolysis and fermentation (CHF) on wheat flour based medium, with $24 \mathrm{~h}$ of pre-hydrolysis: (-口-) glucose; (- $\mathbf{-}-)$ lactic acid; (-—) $\mathrm{pH}$.

After 12 hours of separate hydrolysis the fermentation lasted as long as 44 hours so the total time was the same as in case of SSF process ( 56 hours), but with a better final lactic acid concentration $\left(105 \mathrm{~g} \mathrm{~L}^{-1}\right)$ resulting in a better productivity result (Table 2). Since at the time point of inoculation the glucose concentration was $74 \mathrm{~g} \mathrm{~L}^{-1}$, during fermentation $\sim 50 \mathrm{~g} \mathrm{~L}^{-1}$ additional glucose was produced in line with lactic acid fermentation.
According to our expectations, in case of $\mathrm{CHF}$ with 24 hours of separate hydrolysis the fermentation time decreased (38 hours), since the glucose concentration was $99 \mathrm{~g} \mathrm{~L}^{-1}$ at the inoculation, and final lactic acid concentration was almost the same as in case of CHF with 12 hours of hydrolysis (Table 2). Since total time of process was elevated because of the longer hydrolysis time, the total productivity (calculated with total process time) was lower.

\subsection{Modeling of SSF, CHF and SHF technologies}

Considering the experimental results with $0,12,24$ and $36 \mathrm{~h}$ of inoculation time it can be supposed that there is an optimal inoculation time point. To determine it, we built up an empirical model description of the starch to glucose hydrolysis and integrated it into our lactic acid fermentation kinetic model [16]. Simulating the inoculation at different time points resulted in the productivity curve presented at Fig. 6. According to this, an optimal inoculation time of $14 \mathrm{~h}$ can be derived.

To verify the modeled hypothesis we performed an experiment with this 14 hour inoculation point after the start of the hydrolysis. As Fig. 7 and Table 2 show, this resulted in high yield and productivity.

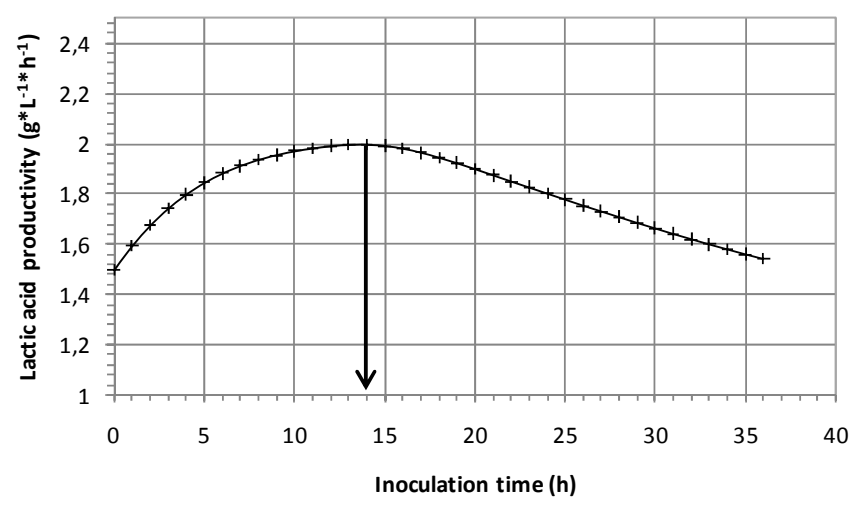

Fig. 6. Effect of inoculation time point on lactic acid volumetric productivity, from simulations based on the integrated hydrolysis and fermentation kinetic model.

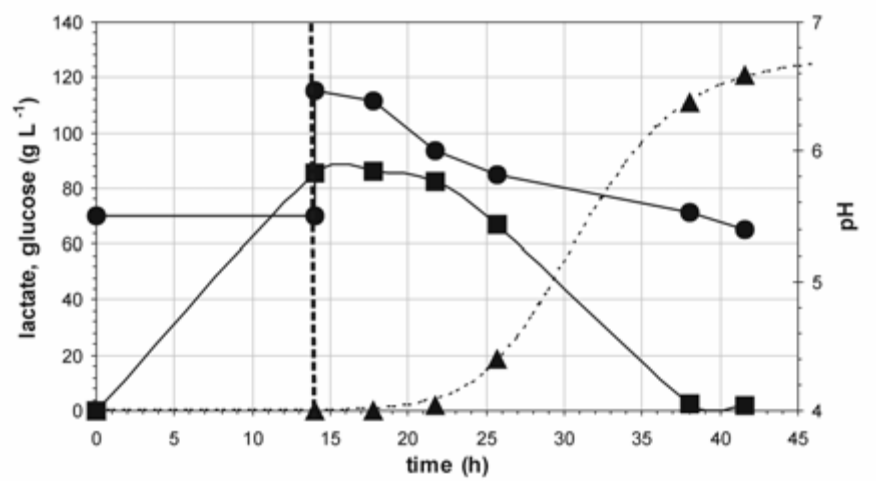

Fig. 7. Verification of the model: combined hydrolysis and fermentation (CHF) on wheat flour based medium, with $14 \mathrm{~h}$ of pre-hydrolysis: (- - -) glu-

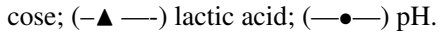




\section{Conclusions}

It has been the target of researchers for a long time to develop successful simultaneous saccharification and fermentation (SSF) for lactic acid (and other fermentation) production processes, but usually some compromises have to be made because of the different optima in $\mathrm{pH}$ and temperature of the two processes. In practice separate hydrolysis and fermentation (SHF) is widely used in starch based lactic acid fermentation technologies, but the overall length of the process makes this technology uneconomic. Applying a time delay in inoculation and cutting down hydrolysis time before fermentation, an optimal inoculation and high efficiency was achieved by experimental work feeding in to a kinetic model. Testing experimentally different settings of separate pre-hydrolysis time $(0,12,24$ and $36 \mathrm{~h})$, combined hydrolysis and fermentation (CHF) technique proved to be the best solution, considering the productivity calculated with the sum of the time of the two processes. The model built from empirical model of starch hydrolysis integrated into a lactic acid fermentation kinetic model gave $14 \mathrm{~h}$ as an optimal inoculation time point. Experimental verification of this model gave excellent productivity results: calculating with only the fermentation time productivity was $4.32 \mathrm{~g} \mathrm{~L}^{-1} \mathrm{~h}^{-1}$, while previous experiments with SHF technology gave only $3.54 \mathrm{~g} \mathrm{~L}^{-1} \mathrm{~h}^{-1}[8]$ on the same optimized wheat based medium. Productivity considering the overall time (time of hydrolysis and fermentation) also approaches the limit of $3 \mathrm{~g} \mathrm{~L}^{-1} \mathrm{~h}^{-1}$, consequently technological optimization was successful.

\section{References}

1 Altaf M, Naveena B J, Venkateshwar M, Kumar E V, Reddy G, Single step fermentation of starch to $L(+)$ lactic acid by Lactobacillus amylophilus GV6 in SSF using inexpensive nitrogen sources to replace peptone and yeast extract - Optimization by RSM, Process Biochemistry 41 (2006), 465-472.

2 Altaf M, Venkateshwar M, Srijana M, Reddy G, An economic approach for L-(+) lactic acid fermentation by Lactobacillus amylophilus GV6 using inexpensive carbon and nitrogen sources, Journal of Applied Microbiology 103 (2007), 372-380.

3 Anuradha R, Suresh A K, Venkatesh K V, Simultaneous saccharification and fermentation of starch to lactic acid, Process Biochemistry 35 (1999), 367-375.

4 Cheng P, Mueller R E, Jaeger S, Bajpai R, lannoti E L, Lactic acid production from enzyme-thinned corn starch using Lactobacillus amylovorus, Journal of Industrial Microbiology and Biotechnology 7 (1991), 27-34.

5 Hang Y D, Direct fermentation of corn to L(+) lactic acid by Rhizopus oryzae, Biotechnology Letters 11 (1989), 299-300.

6 , Direct fermentation of corn to L(+)-lactic acid by Rhizopus oryzae, 1990. United States Patent 4963486.

7 Hetényi K, Németh Á, Sevella B, Fehér biotechnológiai kutatások, Magyar Kémiai Folyóirat 3 (2008), 102-106.

8 . First steps in the development of a wheat flour based lactic acid fermentation technology, Culture Medium Optimization, Chemical and Biochemical Engineering Quarterly 2 (2010).

9 Hofvendahl K, Akerberg C, Zacchi G, Hahn-Hagerdal B, Simultaneous enzymatic wheat starch saccharification and fermentation to lactic acid by Lactococcus lactis, Applied Microbiology and Biotechnology 52 (1999), 163-169.

10 Jie L, Zhang Y C, Comparison of L-lactic acid production by Bacillus coag- ulans and Rhizopus oryzae with fiber waste, Second International Papermaking and Environment Conference, Proceeding, Book A and B, 2008, pp. 146149.

11 Li M, Hanford M J, Kim J W, Peeples T L, Amyloglucosidase enzymatic reactivity inside lipid vesicles, Journal of Biological Engineering 1 (2007), 4.

12 Linko Y Y, Javanainen P, Simultaneous liquefaction, saccharification, and lactic acid fermentation on barley starch, Enzyme and Microbial Technology 19 (1996), 118-123.

13 Ohkouchi Y, Inoue $\mathbf{Y}$, Direct production of $L(+)$-lactic acid from starch and food wastes using Lactobacillus manihotivorans LMG18011, Bioresource Technology 97 (2006), 1554-1562.

14 Mercier P, Yerushalmi L, Rouleau D, Duchain D, Kinetics of lactic acid fermentation on glucose and corn by Lactobacillus amylophilus, J. Chem. Technol. Biotechnol. 55 (1992), 111-121.

15 Nancib A, Nancib N, Meziane-Cherif D, Boubendir A, Fick M, Boudrant $\mathbf{J}$, Join effect of nitrogen sources and $B$ vitamin supplementation of date juice on lactic acid production by Lactobacillus casei subps. rhamnosus, Bioresource Technology 96 (2005), 63-67.

16 Németh Á, Nagy G, Sevella B, New results ont he field of „White Biotechnology”, Hungarian Journal of Industrial Chemistry 37 (2009), 69-167.

17 Parajo J C, Alonso J L, Moldes A B, Production of lactic acid from lignocellulose in a single stage of hydrolysis and fermentation, 1997. United States Patent 1997051099.

18 Polakovic M, Bryjak J, Modelling of potato starch saccharification by an Aspergillus niger glucoamylase, Biochemical Engineering Journal 18 (2004), 57-63.

19 Rodriguez V B, Alameda E J, Gallegos J F M, Requena A R, Lopez A I G, Enzymatic Hydrolysis of Soluble Starch with an $\alpha$-Amylase from Bacillus licheniformis, Biotechnol. Prog. 22 (2006), 718-722.

20 Rojan J P, Nampoothiri K M, Pandey A, Simultaneous saccharification and $L-(+)$-lactic acid fermentation of protease-treated wheat bran using mixed culture of lactobacilli, Biotechnology Letters 28 (2006), 1823-1826.

21 Rojan J P, Sukumaran R K, Nampoothiri K M, Pandey A, Statistical optimization of simultaneous saccharification and $l(+)$-lactic acid fermentation from cassava bagasse using mixed culture of lactobacilli by response surface methodology, Biochemical Engineering Journal 36 (2007a), 262-267.

22 Rojan J P, Nampoothiri K M, Pandey A, Fermentative production of lactic acid from biomass: an overview of process developments and future perspectives, Applied Microbiology and Biotechnology 74 (2007b), 524-534.

23 Rojan J P, G. S. Anisha, Nampoothiri K M, Pandey A, Direct lactic acid fermentation: Focus on simultaneous saccharification and lactic acid production, Biotechnology Advances 27 (2009), 145-152.

24 Ueno T, Maekawa T, L-lactic acid production from potato waste by a membrane reactor with ultrafiltration system, Journal of the Japanese Society for Food Science and Technology 40 (1993), 400-405.

25 Wee Y J, Reddy L V A, Ryu H W, Fermentative production of L(+)-lactic acid from starch hydrolyzate and corn steep liquor as inexpensive nutrients by batch culture of Enterococcus faecalis RKY1, Journal of Chemical Technology and Biotechnology 83 (2008), 1387-1393. 